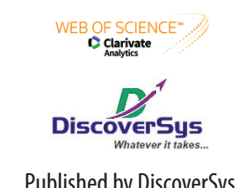

Published by DiscoverSys

\section{Urban Space Preferences among Older Adults from a Sociodemographic Perspective}

\author{
Bahare Fallahi, ${ }^{1}$ Yadollah Abolfathi Momtaz ${ }^{2 *}$
}

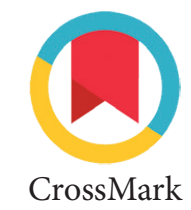

\section{ABSTRACT}

Background: The population of Iran is rapidly aging, and there is no specific housing policy and urban space planning for the elderly. It is vital and necessary to consider urban space and residential environment in order to meet elderly's different needs, preferences, desires, and aspirations to maintain and improve their quality of life (0OL).

Aim: This study aims to evaluate the aging urban space and residential preference because urban space situation influences the residential satisfaction that leads to the quality of life.

Methods: In this study, 400 old adults residing in Karaj, Iran were surveyed. Independent sample t-test was used to examine the relationship between socio-demographic factors and urban space preferences.

Results: There are no differences among genders for urban space preferences, but there are differences in marital status for urban space preferences among elderlies in Karaj, Iran. The results also showed that most participants emphasized Convenience, Accessibility followed by Safety, and Citizen Participation.

Conclusion: Marital status was found to play a significant role in urban space preferences.
${ }^{1}$ Ph.D. Housing Policy, University of Putra, Malaysia

${ }^{2}$ Iranian Research Center on Aging, University of Social Welfare and Rehabilitation, Tehran, Iran/ Malaysia, Serdang, Selangor, Malaysia

*Correspondence to: Yadollah Abolfathi Momtaz, Iranian Research Center on Aging, University of Social Welfare and Rehabilitation, Tehran, Iran/ Malaysia, Serdang, Selangor, Malaysia

yabolfathi@gmail.com

Received: 2018-05-14 Accepted: 2018-5-21 Published: 2018-8-1

Keywords: residential preferences, aging, urban space, Karaj, Iran.

Cite This Article: Fallahi,B., Momtaz, Y.A. 2018. The relationship between gender and marital status and urban space preferences among elderlies in Karaj, Iran. Bali Medical Journal 7(3): 544-549. D0l:10.15562/bmj.v7i3.1183

\title{
INTRODUCTION
}

Nowadays, some mechanisms are offered in many countries to promote the elderly's quality of life (QOL). An important factor affecting the QOL is an urban area. According to Akbari Neisiani, et al. (2016), the aging preferences of urban space are different from the others because of mental and physical problems. ${ }^{1}$ The development of policies and strategies, which considers aging requirements and desires, can improve QOL. ${ }^{2}$ The elderly are also dependent on the amenities available in the urban space. Neighborhood facilities and services in urban space are vital and important for this group. Moreover, supportive urban space for welfare for all age groups is an area priority in the World Health Organization's (WHO) strategy for welfare in Europe. ${ }^{3}$ Make sure a "better fit" amongst aging inhabitants and urban spaces is recognized as an issue of earnestness in the interior social policy, a significant policy for local action on health equity, and a key matter for the inclusive, sustainable urban planning. ${ }^{4}$ A growing body of study is showing the influence of the neighborhood and urban space on elderly health, activity, and welfare., ${ }^{5,6}$ The significant dimensions and structures, and more generally, how to conceptualize and implement age-friendly societies, ${ }^{7,8}$ are nonetheless a subject of debate.

A recently important section is the formation of walkable public areas and actively living societies. ${ }^{9}$
Growing evidence on the significance of social and physical neighborhood variables for the elderly's participation and QOL ${ }^{10,11}$ emphasizes the advantages of cooperation among the public health and urban planning to design the environment supporting the people of all ages and abilities.

Tan (2012) claimed that selecting a place is a multidimensional exercise comprising neighborhoods and locations, so neighborhood preferences are determined by several features. ${ }^{12,13}$ The preferences might be considered different factors such as the access to neighborhood facilities and the quality of the natural environment. ${ }^{14}$ In addition, urban area preferences refer to residents' overall assessment of their neighborhood and environment. ${ }^{15}$ Rojo Perez et al. in their article "Ageing in place: predictors of the elderly's residential satisfaction" have shown the impact of neighborhood on the elderly's satisfaction in Madrid and indicated that satisfaction influenced the street conditions and tracked works. ${ }^{16}$ In a sample of aging U.S citizens, the results showed that certain urban characteristics such as safety, quietness, cleanliness, and proximity to amenities were found to be connected to urban space satisfaction. ${ }^{17}$ On the contrary, Tan (2011) stated that the neighborhood facilities such as being close to the hospital and sports centers have an insignificant relationship with the elderly's urban 
space satisfaction..$^{18}$ In Greenville, North Carolina, findings revealed that the crime rate in urban area influences the residential satisfaction. ${ }^{15}$ A similar finding was reported by Rashid in Iraq who found that people select the neighborhood with respect to security, neighborhood facilities and social environment significantly related to their level of urban space satisfaction. ${ }^{19}$ In an aging sample, the impact of urban space on satisfaction was studied. The results indicated that security and access to green areas were related to aging urban space satisfaction..$^{20}$ Ge and Hokao (2006) conducted a study to examine the residential preferences in Japan. They found that neighborhood facilities such as access to shops, public transportations, and sports centers impact the urban space satisfaction..$^{21}$

\section{METHODS}

\section{Research methods}

This is a quantitative study. The questionnaire survey provided information on the urban space preferences variables hypothesized to promote the residential satisfaction among 400 elderlies in order to enhance the QOL. The target population is the elderlies residing in Karaj, Iran. The study identified elderlies aged 60 and over. For selecting the sample size, the researcher used Cochran (1977) proposed using equation to determine the size. ${ }^{22}$ In this study, convenience sampling was used for sampling. ${ }^{13,15,16}$

\section{Instruments}

As a data collection tool, the questionnaire is well accepted within the urban space paradigm. Multiple questionnaires have been developed to assess the aging preferences in urban space. Cross-sectional surveys have been used in several previous studies to investigate the aging urban space. Face-to-face interviews were conducted. This allowed for increased response rate and the inclusion of elderlies with limited access to the Internet or limited ability to read or write. The questionnaire was modified from previous studies, and involved eight variables based on a 5-point Likert scale; each construct had five items to measure. The questionnaire was pilot tested among 30 respondents to examine the reliability. All items showed good reliability values. The variables are as follows: accessibility, convenience, safety, citizen participation, vitality and dynamism, culture facility, control and monitoring, legibility.

The Statistical Package for the Social Sciences software (SPSS; Version 16) was used to analyze the data. This involved two steps:
1. Descriptive statistics were used to describe the sample characteristics and find patterns in the data.

2. Independent group's t-test was used to test the study hypotheses.

\section{Study area}

Alborz Province is one of the 31 Iran's provinces, centered in Karaj. Salleh (2008) found that the main factors determining preferences in urban area are neighborhood services, safety infrastructure, and central facilities. ${ }^{23}$ Hosting a population around 1.96 million, as recorded in the 2011 Census, Karaj has 110,000 elderlies. It is the fourth-largest city in Iran, after Tehran, Mashhad, and Isfahan. ${ }^{24}$

\section{RESULTS}

\section{Characteristics of samples}

The socioeconomic characteristics of the residents showed that most of them were married, and the majority of respondents were males. The majority had certificates below high school. Furthermore, the majority was retired (Table 1).

\section{Preference perceived by the elderlies in Karaj, Iran}

In this section, the descriptive data on the level of urban space preferences amongst the respondents are presented. Table 2 shows the inhabitants' preferences, most of which emphasized Convenience (94\%) followed by Safety (92.7\%), and Citizen Participation (92.2\%).

\section{Hypothesis}

H0: There is no significant relationship between marital status and urban space preferences.

H0: There is no significant relationship between gender and urban space preferences.

Bivariate analyses, independent $\mathrm{t}$-test were conducted to examine the relationship between the socio-demographic factors and elderly's urban space preferences in Karaj, Iran.

An independent sample t-test was conducted to compare the urban space preferences between male and female respondents. As shown in Table 3, there was no significant difference in terms of urban space preferences among male and female. The result showed that there are no differences among genders for urban space preferences. Thus no significant differences were found in terms of the mean scores among the groups. The study assumed that the population variances are relatively equal. The $t$-test significance indicates $p>0.05$ and therefore is not significant. As a result, the null 
Table 1 Socio-demographic characteristics of the respondents

\begin{tabular}{|c|c|c|c|c|}
\hline \multicolumn{2}{|c|}{ Demographic characteristics } & \multirow{2}{*}{$\frac{\mathbf{n}}{212}$} & \multirow[t]{2}{*}{$\mathbf{M}$} & \multirow[t]{2}{*}{ SD } \\
\hline Sex & Male & & & \\
\hline & Female & 187 & & \\
\hline & & & 71.82 & 7.773 \\
\hline \multirow[t]{5}{*}{ Education } & Secondary & 72 & & \\
\hline & Diploma & 27 & & \\
\hline & Bachelor & 12 & & \\
\hline & Master & 4 & & \\
\hline & Primary school & 284 & & \\
\hline \multirow{6}{*}{$\begin{array}{l}\text { Occupation } \\
\text { Status }\end{array}$} & Unemployed & 19 & & \\
\hline & Retiree & 209 & & \\
\hline & Work at Company & 34 & & \\
\hline & Self-employed with no workers & 120 & & \\
\hline & Self-employed with workers & 8 & & \\
\hline & Work for Government & 9 & & \\
\hline \multirow[t]{5}{*}{ Marital Status } & Single & 20 & & \\
\hline & Married & 271 & & \\
\hline & Divorced & 17 & & \\
\hline & Widowed & 87 & & \\
\hline & Separated & 4 & & \\
\hline
\end{tabular}

Table 2 Distribution of urban space preferences

\begin{tabular}{|c|c|c|c|c|c|c|}
\hline \multirow{3}{*}{ Variable } & \multicolumn{6}{|c|}{ Range value } \\
\hline & \multicolumn{2}{|c|}{ Low } & \multicolumn{2}{|c|}{ Moderate } & \multicolumn{2}{|c|}{ High } \\
\hline & $\%$ & $\mathbf{n}$ & $\%$ & $\mathbf{n}$ & $\%$ & $\mathbf{n}$ \\
\hline Accessibility & 0.8 & 3 & 19.3 & 77 & 79.9 & 319 \\
\hline Convenience & 0.5 & 2 & 5.5 & 22 & 94 & 375 \\
\hline Safety & 0.5 & 2 & 6.8 & 27 & 92.7 & 370 \\
\hline Citizen's Participation & 0.8 & 3 & 7 & 28 & 92.2 & 368 \\
\hline $\begin{array}{l}\text { Vitality and } \\
\text { Dynamism }\end{array}$ & 0.8 & 3 & 12.3 & 49 & 87 & 347 \\
\hline Legibility & 1 & 4 & 8 & 32 & 91 & 363 \\
\hline $\begin{array}{l}\text { Control and } \\
\text { Monitoring }\end{array}$ & 0.5 & 2 & 11.3 & 45 & 88.2 & 352 \\
\hline Cultural Facility & 8.3 & 33 & 25.8 & 103 & 65.9 & 263 \\
\hline
\end{tabular}

hypothesis is accepted and the alternative hypothesis is rejected; for Accessibility $\mathrm{p}>0.05=0.870$; Convenience, $\mathrm{p}>0.05=0.45$; Safety, $\mathrm{p}>0.05=$ 0.89; Citizen's Participation, $p>0.05=0.94$; Vitality and Dynamism, $\mathrm{p}>0.05=0.187$; Legibility, p> 0.05 $=0.057$; Control and Monitoring, $\mathrm{p}>0.05=0.61$, Cultural Facility, $\mathrm{p}>0.05=0.48$.

Another independent sample t-test was conducted to compare the urban space preferences between married and unmarried respondents (Table 4).

An independent sample t-test was conducted to compare the urban space preferences between unmarried and married respondents. As shown in Table 4, there was a significant difference in urban space preferences between unmarried and married respondents. Thus, the result showed that there are differences between unmarried and married respondents in terms of elderly's urban space preferences in Karaj, Iran. Thus, a significant difference was found in terms of mean scores between the groups. The t-test significance indicates $\mathrm{p} \leq .05$ and therefore is significant, and the null hypothesis is rejected and the alternative hypothesis is accepted; Accessibility $\mathrm{p} \leq .05=0.021$; Convenience $\mathrm{p} \leq .05$ $=0.007$; Safety, $\mathrm{p} \leq .05=0.029$; Citizen's Participation, $\mathrm{p} \leq .05=0.000$; Vitality and Dynamism, $\mathrm{p} \leq .05=0.002$; Legibility, $\mathrm{p} \leq .05=0.001$; Control and Monitoring, $\mathrm{p} \leq .05=0.003$. There are differences between unmarried and married participants in terms of elderly's urban space preferences Karaj, Iran. However, for Culture facility, $p>0.05=0.35$ there is no difference between unmarried and married participants in this regard. Thus, no significant differences are found in terms of the mean scores (Table 4).

\section{DISCUSSION}

According to the WHO (2007) model of age-friendly communities and existing lines of discussion in aging preferences in urban area, the present study found that most of the elderlies emphasized Convenience, Accessibility followed by Safety and Citizen's Participation in urban space which are consistent with the findings by $\mathrm{Lu}$ (1999) and Speare (1974). ${ }^{25,26}$ They found that residents put emphasis on neighborhood characteristics such as social environment. Similarly, Fang (2006), Mohit and Azim (2012), Oh (2003), Kauko (2006) and Wang and Li (2006) stated that neighborhood facilities and social environment are among the important factors emphasized by the public and affect urban space satisfaction..$^{27-31}$ To support these findings, a conceptual approach developed by Speare (1974) and Fredrickson et al. (1980) was adopted to understand and explain the residential preferences. They argued that location and social bonds are important factors in evaluating a place by the public and are measured in relation to a person's threshold for dissatisfaction. ${ }^{26,32}$

The results of the independent group t-test showed that there was no significant difference in urban space preferences between male and female. Thus, the result showed that there are no differences 
Table 3 Mean scores of urban space according to socioeconomic factors

\begin{tabular}{|c|c|c|c|c|c|c|}
\hline Variable & & $\mathbf{n}$ & $P$ value & $\mathbf{t}$ & SD & M \\
\hline \multirow[t]{2}{*}{ Accessibility } & Female & 187 & 0.87 & 0.50 & 4.92 & 37.37 \\
\hline & Male & 212 & & & 4.58 & 37.13 \\
\hline \multirow[t]{2}{*}{ Convenience } & Female & & 0.45 & -0.37 & 3.79 & 38.04 \\
\hline & Male & & & & 2.93 & 38.16 \\
\hline \multirow[t]{2}{*}{ Safety } & Female & & 0.89 & -1.15 & 1.86 & 17.05 \\
\hline & Male & & & & 1.57 & 17.25 \\
\hline \multirow[t]{2}{*}{ Citizen Participation } & Female & & 0.94 & 0.68 & 2.06 & 16.99 \\
\hline & Male & & & & 1.63 & 16.86 \\
\hline \multirow[t]{2}{*}{ Vitality and Dynamism } & Female & & 0.187 & -1.72 & 1.62 & 12.52 \\
\hline & Male & & & & 1.28 & 12.77 \\
\hline \multirow[t]{2}{*}{ Legibility } & Female & & 0.057 & -0.06 & 1.267 & 8.45 \\
\hline & Male & & & & 0.949 & 8.68 \\
\hline \multirow[t]{2}{*}{ Control and Monitoring } & Female & & 0.61 & -0.67 & 1.48 & 12.86 \\
\hline & Male & & & & 1.27 & 12.95 \\
\hline \multirow[t]{2}{*}{ Culture Facility } & Female & & 0.48 & -0.98 & 3.67 & 14.80 \\
\hline & Male & & & & 3.45 & 15.15 \\
\hline
\end{tabular}

${ }^{*} \mathrm{p} \leq .05,{ }^{* *} \mathrm{p}<.01$

Table 4 Mean scores of urban space preferences according to socioeconomic factors

\begin{tabular}{|c|c|c|c|c|c|c|}
\hline Variable & & $\mathbf{n}$ & $P$ value & $\mathbf{t}$ & SD & M \\
\hline \multirow[t]{2}{*}{ Accessibility } & Unmarried & 128 & $0.021^{\star *}$ & 0.89 & 5.786 & 37.5859 \\
\hline & Married & 271 & & & 4.15 & 37.0812 \\
\hline \multirow[t]{2}{*}{ Convenience } & Unmarried & & $0.007^{\star *}$ & -0.983 & 4.41 & 37.82 \\
\hline & Married & & & & 2.72 & 38.24 \\
\hline \multirow[t]{2}{*}{ Safety } & Unmarried & & 0.029 ** & -2.66 & 2.095 & 16.78 \\
\hline & Married & & & & 1.47 & 17.33 \\
\hline \multirow[t]{2}{*}{ Citizen's Participation } & Unmarried & & $0.000^{\star *}$ & -2.17 & 2.44 & 16.58 \\
\hline & Married & & & & 1.46 & 17.08 \\
\hline \multirow{2}{*}{$\begin{array}{l}\text { Vitality and } \\
\text { Dynamism }\end{array}$} & Unmarried & & $0.002^{* *}$ & -2.63 & 1.81 & 12.34 \\
\hline & Married & & & & 1.23 & 12.80 \\
\hline \multirow[t]{2}{*}{ Legibility } & Unmarried & & $0.001^{\star \star}$ & -3.93 & 1.42 & 8.21 \\
\hline & Married & & & & 0.88 & 8.75 \\
\hline \multirow{2}{*}{$\begin{array}{l}\text { Control and } \\
\text { Monitoring }\end{array}$} & Unmarried & & $0.003^{\star \star}$ & -2.67 & 1.65 & 12.6094 \\
\hline & Married & & & & 1.20 & 13.0443 \\
\hline \multirow[t]{2}{*}{ Cultural Facility } & Unmarried & & 0.35 & -0.25 & 3.79 & 14.92 \\
\hline & Married & & & & 3.45 & 15.02 \\
\hline
\end{tabular}

${ }^{*} \mathrm{p} \leq .05,{ }^{* *} \mathrm{p}<.01$ urban space. Therefore, the first hypothesis was not confirmed. This finding did not support previous studies which found gender differences in terms of urban space preferences among elderlies. ${ }^{33-35}$

Another independent sample t-test was conducted to compare the urban space preferences between married and unmarried respondents. Significant differences were found in terms of mean scores among the groups, and the study assumed that the population variances were not relatively equal. Therefore, the second hypothesis was confirmed. This finding was consistent with the findings by Ham and Feijten (2008) who found a relationship of neighborhood preferences with the household size and number of children. ${ }^{36}$ This result supported residential mobility theory by Rossi (1955) and Dieleman (2001) which stated that household size and marital status determine the choice of a neighborhood. ${ }^{37,38}$ The increase in household size might increase the neighborhood preferences and expectations in the neighborhood such as preferences to access more facilities and services. This finding was also parallel with those recorded by Wang and Li (2004), Gentile ( 2005), Adelman (2005) and Boehm and Schlottmann (2006) who stated that socio-demographic characteristics influence the urban space and neighborhood preferences. ${ }^{39-42}$

This study may provide important insights for decision-makers to assess priorities during the implementation process of neighborhood developments to enhance the elderly's QOL. In urban planning, convenience, safety and security, and citizen's participation are viewed as a vital element that influences satisfaction and QOL and is an important urban planning issue to address.

\section{CONCLUSION}

Since urban space and the factors that might maintain the residential preferences in Karaj, Iran was not studied adequately; this study aimed to determine the relationship between the socio-demographic factors and urban space preferences. The findings of this applied study add to the growing body of literature in the area of ecological aging person-environment fit. Marital status was found to play a significant role in urban space preferences. Our findings highlight the importance of Convenience followed by Safety and Citizen's Participation in urban space important for the elderlies in urban space. These preferences create a challenge for natural resource agencies and policymakers in order to provide appropriate neighborhood and environment for the elderlies in the urban areas and wish 
to reach out a better serving of these residents. Survey results can also potentially inform policymakers by management and improvement of one's environment fit. Perhaps current services, activities, and amenities do not match the elderly's desires, needs, aspirations, and preferences. Perhaps there are other structural constraints that limit the participation. Future study of recreation preferences among diverse urban populations can extend these findings by exploring how other demographic and social factors (e.g., ethnicity) influence the preferences and behaviors examined in the present research. To further explore the role of age in determining urban space preferences and policy decisions, such study could examine data using a multi-method (i.e., qualitative and quantitative) and longitudinal approach.

\section{LIMITATIONS}

As with other studies, there are some limitations on this research, which might offer opportunities for future study. The first is the cross-sectional nature of this research, which prevents the possibility of drawing conclusions about casual associations amongst the variables. This research considered the association amongst socio-demographic factors and urban space preferences. This study was conducted among elderlies and only in Karaj, not in the whole of Iran.

\section{DIRECTIONS FOR FURTHER RESEARCH}

Since this study is one of the very few studies examining the impact of socio-demographic factors on urban space preferences among the elderlies in Karaj, Iran, it might provide opportunities for future studies. Future studies among larger samples of elderlies from different countries and cultures are needed to validate the results of this study. As little is known about the ways to promote satisfaction among elderlies, it is suggested that future studies focus on how to strengthen satisfaction in urban space and neighborhood. Since this study was conducted in a cross-sectional design, a longitudinal study is required to clarify the causal relationship between urban space preferences and residential satisfaction.

\section{ACKNOWLEDGEMENT}

The authors are thankful to the study participants. This study was supported by grant No 1358 in university of Social Welfare and Rehabilitation Science, Tehran, Iran.

\section{REFERENCES}

1. Akbari Neisiani, B., Seyedan, S. M., \& Radfar, E. (2016). Urban green spaces assessment approach to health, safety and environment. International Journal of Human Capital in Urban Management, 1(2), 123-132.

2. Turel, H. S., Yigit, E. M., \& Altug, I. (2007). Evaluation of elderly people's requirements in public open spaces: A case study in Bornova District (Izmir, Turkey). Building and Environment, 42(5), 2035-2045.

3. World Health Organization. (2007). Global age-friendly cities: A guide. Retrieved from http:// whqlibdoc.who.int/ publications/2007/9789241547307_eng.pdf?

4. Barton, H., \& Grant, M. (2006). A health map for the local human habitat. The Journal for the Royal Society for the Promotion of Health, 126(6), 252-253.

5. Clarke, P., \& Nieuwenhuiisen, E. R. (2009). Environments for healthy ageing: a critical review. Maturitas, 64(1), 14-19.

6. Yen, I. H., Michael, Y. L., \& Perdue, L. (2009). Neighborhood environment in studies of health of older adults: a systematic review. American journal of preventive medicine, 37(5), 455-463.

7. Buffel, T., Phillipson, C., \& Scharf, T. (2012). Ageing in urban environments: Developing 'age-friendly'cities. Critical Social Policy, 32(4), 597-617.

8. Cachadinha, C. (2012). Characteristics of an age-friendly neighbourhood built environment: comparison of agefriendly community models with empirical evidence. In Proceedings of the 38th IAHS World Congress on Housing Science. Istanbul: Istanbul Technical University, International Association for Housing Science (pp. 677-683).

9. Sallis, J. F., Cervero, R. B., Ascher, W., Henderson, K. A., Kraft, M. K., \& Kerr, J. (2006). An ecological approach to creating active living communities. Annu. Rev. Public Health, 27, 297-322.

10. Van Cauwenberg, J., De Bourdeaudhuij, I., De Meester, F., Van Dyck, D., Salmon, J., Clarys, P., \& Deforche, B. (2011). Relationship between the physical environment and physical activity in older adults: a systematic review. Health \& place, $17(2), 458-469$.

11. Kerr, J., Rosenberg, D., \& Frank, L. (2012). The role of the built environment in healthy aging: community design, physical activity, and health among older adults. CPL bibliography, 27(1), 43-60.

12. Tan, T. H. (2012). Meeting first-time buyers' housing needs and preferences in greater Kuala Lumpur. Cities, 29(6), 389-396.

13. Hurtubia, R., Gallay, O., \& Bierlaire, M. (2010). Attributes of households, locations and real-estate markets for land use modeling. Sustain City Deliverable, 2.

14. Menchik, M. (1972). Residential environmental preferences and choice: empirically validating preference measures. Environment and Planning A, 4(4), 445-458.

15. Hur, M., Nasar, J. L., \& Chun, B. (2010). Neighborhood satisfaction, physical and perceived naturalness and openness. Journal of Environmental Psychology, 30(1), 52-59.

16. Rojo Perez, F., Fernandez-Mayoralas Fernandez, G., Pozo Rivera, E., \& Manuel Rojo Abuin, J. (2001). Ageing in place: Predictors of the residential satisfaction of elderly. Social Indicators Research, 54(2), 173-208.

17. Carp, F. M., \& Christensen, D. L. (1986). Technical environmental assessment predictors of residential satisfaction: A study of elderly women living alone. Research on Aging, 8(2), 269-287.

18. Tan, T. H. (2011). Determinants of housing satisfaction in Klang Valley, Malaysia. School of Business Occasional Paper Series No. 2. Sunway University.

19. Rashid, S. T., bin Ngah, I., \& Eluwa, S. E. (2013). Neighbourhood choice factors and residents satisfaction in old and new neighborhoods of Slemani City, KurdistanIraq. Journal of Environment and Earth Science, 3(2), 72-80.

20. Kahana, E., Kahana, B., \& Kercher, K. (2003). Emerging lifestyles and proactive options for successful ageing. Ageing International, 28(2), 155-180. 
21. Ge, J., \& Hokao, K. (2006). Research on residential lifestyles in Japanese cities from the viewpoints of residential preference, residential choice and residential satisfaction. Landscape and urban planning, 78(3), 165-178.

22. Cochran, W.G. (1977). Sampling Techniques, 3rd Edition. New York: John Wiley \& Sons, Inc.

23. Salleh, A. G. (2008). Neighbourhood factors in private low-cost housing in Malaysia. Habitat International, 32(4), 485-493.

24. Irani, M.(2016). Population in Karaj. http://www.mehrnews.com.

25. Lu, M. (1999). Determinants of residential satisfaction: ordered logit vs. regression models. Growth and Change, 30(2), 264-287.

26. Speare, A. (1974). Residential satisfaction as an intervening variable in residential mobility. Demography, 11(2), 173-188.

27. Fang, Y. (2006). Residential satisfaction, moving intention and moving behaviours: a study of redeveloped neighbourhoods in inner-city Beijing. Housing Studies, 21(5), 671-694.

28. Mohit, M. A, \& Azim, M. (2012). Assessment of residential satisfaction with public housing in Hulhumale, Maldives. Procedia - Social and Behavioral Sciences, 50, 756-770.

29. Oh, JH. (2003). Social bonds and the migration intentions of elderly urban residents: The mediating effect of residential satisfaction. Population Research and Policy Review, 22(2), 127-146.

30. Kauko, T. (2006). Expressions of housing consumer preferences: proposition for a research agenda. Housing, Theory and Society, 23(2), 92-108.

31. Wang, D, \& Li, S. (2006). Socio-economic differentials and stated housing preferences in Guangzhou, China. Habitat International, 30(2), 305-326.

32. Fredrickson, C, Heaton, T. B., Fuguitt, G. V., \& Zuiches, J. (1980). Residential preferences in a model of migration intentions. Population and Environment, 3(3-4), 280-297.

33. Berween, M. (2002). The fundamental human rights: an islamic perspective. The International Journal of Human Rights, 6(1), 61-79.
34. Jabareen, Y. (2005). Culture and housing preferences in a developing city. Environment and Behavior, 37(1), 134-146.

35. Opoku, R. A., \& Abdul-Muhminb, A. G. (2010). Housing preferences and attribute importance among low-income consumers in Saudi Arabia. Habitat International, 34(2), 219-227.

36. Ham, M. V, \& Feijten, P. (2008). Who wants to leave the neighbourhood? The effect of being different from the neighbourhood population on wishes to move. Environment and Planning 40(5), 1151 - 1170.

37. Rossi, P.H. (1955). Why families move. A study in the social psychology of Urban residential mobility: Glencoe.

38. Dieleman, F. M. (2001). Modelling residential mobility; a review of recent trends in research. Journal of Housing and the Built Environment, 16(3-4), 249-265.

39. Wang, D, \& Li, S. (2004). Housing preferences in a transitional housing system: the case of Beijing, China. Environment and Planning, 36(1), 69-88.

40. Gentile, M. (2005). Urban residential preferences and satisfaction in the former Soviet Union: results from a survey in Ust'-Kamenogorsk, Kazakhstan. Urban Geography, 26(4), 296-327.

41. Adelman, R. M. (2005). The roles of race, class, and residential preferences in the neighborhood racial composition of middle-class blacks and whites. Social Science Quarterly, 86(1), 209-228.

42. Boehm, T. P., \& Schlottmann, A. (2006). A comparison of household mobility for owned manufactured, traditional owned, and rental units using the American Housing Survey. Journal of Housing Economics, 15(2), 126-142.

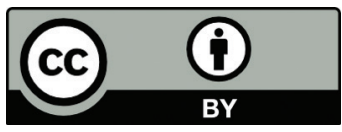

This work is licensed under a Creative Commons Attribution 